\section{A doença mental no direito penal brasileiro: inimputabilidade, irresponsabilidade, periculosidade $e$ medida de segurança}

\section{Mental illness in Brazilian penal law: legal irresponsibility, potentiality for danger/aggressiveness and safety policies}

Este artigo tem como base a dissertação de mestrado Doença e delito: relação entre prática psiquiátrica e poder judiciário no Hospital de Custódia e Tratamento de Salvador, Babia, defendida no programa de pós-graduação do Instituto de Saúde Coletiva da Universidade Federal da Bahia, com bolsa do CNPq e CAPES em momentos distintos.

Maria Fernanda Tourinho Peres

Pesquisadora do Núcleo de Estudos da Violência, Universidade de São Paulo (USP) mftperes@usp.com.br

Antônio Nery Filho

Professor do Departamento de Anatomia Patológica e Medicina Legal da Faculdade de Medicina da

Universidade Federal da Bahia (UFBA) neryfilho@uol.com.br
PERES, M. F. T. e NERY FILHO, A.: 'A doença mental no direito penal brasileiro: inimputabilidade, irresponsabilidade, periculosidade e medida de segurança'. História, Ciências, Saúde-Manguinhos, Rio de Janeiro, vol. 9(2):335-55, maio-ago. 2002.

A prática e o saber psiquiátricos constroem-se em estreita relação com o campo da justiça criminal, questionando os pressupostos da doutrina clássica do direito penal, tais como responsabilidade e livre-arbítrio.

Pretendemos analisar os artigos que tratam da doença mental nos códigos penais brasileiros, desde o Código Criminal do Império do Brazil, datado de 1830. Nosso objetivo é descrever a constituição do estatuto jurídico penal dos doentes mentais no Brasil e do modelo de intervenção penal na vida daqueles indivíduos considerados "perigosos" e "irresponsáveis". Para isso analisamos não só os artigos específicos dos códigos penais, mas também textos de juristas comentadores. Aproveitamos ainda para discutir os conceitos que sustentam o doente mental criminoso em seu lugar de ambigüidade: inimputabilidade, irresponsabilidade, periculosidade e medida de segurança.

PALAVRAS-CHAVE: psiquiatria e direito penal, irresponsabilidade, inimputabilidade, periculosidade, medida de segurança.

PERES, M. F. T. e NERY FILHO, A.: 'Mental illness in Brazilian penal law: legal irresponsibility, potentiality for danger/ aggressiveness and safety policies'. História, Ciências, Saúde - Manguinhos, Rio de Janeiro, vol. 9(2):335-55, May-Aug. 2002. Psychiatric information and practice are closely related with the field of criminal law, questioning classical penal law premises, such as responsibility and freewill. We have analyzed the articles related to mental health in Brazilian penal laws, since Código Criminal do Império do Brazil (Brazilian Empire criminal laws) from 1830. Our objective is to describe the structuring of a legal status for the mentally ill in Brazil, as well as the model of penal intervention in the lives of those considered as 'dangerous' and 'irresponsible'. In order to do so, we have analyzed not only specific articles on penal law, but also texts by specialized analysts. In addition, we have discussed the concepts that keep mentally-ill criminals in a rather ambiguous situation, i.e. legal irresponsibility, potential aggressiveness and safety policies.

KEYWORDS: psychiatry and penal law, irresponsibility, potentiality for danger and safety policies. 


\section{Introdução}

A relação estabelecida entre doença mental e violência ocupou um lugar estratégico na formação da medicina mental no século XIX, e deu margem a uma série de discussões entre alienistas e magistrados. A prática e o saber psiquiátricos constroem-se, dessa forma, em estreita relação com o campo da justiça criminal, questionando os pressupostos da doutrina clássica do direito penal tais como responsabilidade e livre-arbítrio (Castel, 1978; Harris, 1993; Foucault, 1991, 1990). Ao aderir às orientações teóricas da degenerescência formuladas por Morel e às propostas da antropologia criminal fundada por Lombroso, a psiquiatria amplia as fronteiras da "anormalidade" e atua como instância de controle social (Engel, 1999). No Brasil, apesar da especificidade na recepção de teorias desenvolvidas na Europa e do desenvolvimento tardio do alienismo, a atuação psiquiátrica esteve de acordo com o projeto de construção da nação e de manutenção da ordem social (Machado et alii, 1978; Cunha, 1986; Schwarcz, 1995; Engel, 1999). A relação entre loucura e criminalidade, bem como a constituição de instituições de controle e regeneração, ocuparam o cenário de discussões teóricas e implementações políticas (Fry, 1985, 1982; Carrara, 1998; Corrêa, 1998). Neste processo, a relação com o campo do direito criminal ocupou um lugar de destaque, e gerou grandes debates entre alienistas e magistrados que culminaram com a constituição de um modelo de intervenção penal específico para os doentes mentais delinqüentes.

Pretendemos analisar os artigos que tratam da doença mental nos códigos penais brasileiros, desde o Código Criminal do Império do Brazil, datado de 1830. Nosso objetivo é acompanhar a constituição do estatuto jurídico penal dos doentes mentais no Brasil e do modelo de intervenção penal naqueles indivíduos considerados "perigosos" e "irresponsáveis". Para isso analisamos não só os artigos específicos dos códigos penais, mas também textos de juristas comentadores. Aproveitamos ainda para discutir os conceitos que sustentam o doente mental criminoso em seu lugar de ambigüidade: inimputabilidade, irresponsabilidade, periculosidade e medida de segurança.

\section{Os loucos de todo gênero}

Seguindo os preceitos da escola clássica do direito penal, o projeto do Código Criminal do Império do Brazil foi aprovado em 22 de outubro de 1830 e sancionado em 16 de dezembro do mesmo ano pelo imperador d. Pedro I (Chaloub, 1981, p. 17). As bases da doutrina clássica do direito penal foram estabelecidas em 1767 por Cesare Beccaria e se firmavam em três pressupostos: igualdade dos homens perante a lei; pena como função da gravidade do delito; e condicionamento do crime à sua definição legal. A caracterização de um ato como delituoso independia dos atributos pessoais de quem o praticava, como nos 
mostra o artigo 1: "Não haverá crime ou delito sem uma lei anterior que o qualifique" (Brazil, 1876). Para compreendermos o lugar do doente mental no Código Criminal, é importante considerarmos que, além do pressuposto da igualdade e do caráter retributivo da pena, a escola clássica fundamentava-se na doutrina do livre-arbítrio e na noção de responsabilidade.

A presença da loucura como móvel do crime punha em questão os pilares da doutrina clássica do direito. Um homem cujo crime foi cometido em estado de loucura poderia ser considerado responsável? Era livre em sua ação o homem que, na loucura, estava privado dos sentidos? Para lidar com este problema, ditava o nosso código criminal:

Art 10: ... não se julgarão criminosos:

$\S 2$. Os loucos de todo gênero, salvo se tiverem lúcidos intervalos e neles cometerem o crime.

A possibilidade de uma loucura lúcida, como mais tarde viria a ser formulada por Pinel e Esquirol (Carrara, 1998), ainda não estava presente naquele momento; ao contrário, a lucidez marcava o retorno ao estado de razão, e conferia ao louco o estatuto de criminoso. Compreendida ainda entre nós dentro de uma concepção intelectualista, a loucura era desrazão (Machado et alii, 1978). A vontade e as paixões ainda não estavam presentes na teoria sobre a loucura, e os loucos de todo gênero não precisavam de especialistas para serem reconhecidos. "O juiz de direito (era) obrigado a formular quesito sobre o estado de loucura do réu, quando lhe for requerido" e o "exame" deveria ser feito diante do júri, "que é quem devia apreciá-lo para decisão ... . A circunstância da loucura, ainda que de notoriedade pública, só podia ser tomada em consideração pelo júri” (Filgueiras-Jr., 1876, p. 12).

Que destino seria dado a esses loucos que cometem crime mas não são criminosos? É importante lembrarmos que o asilo ainda não tinha surgido entre nós, não havia um lugar específico para a loucura, apenas as prisões e os hospitais da Santa Casa (Machado et alii, 1978; Amarante, 1994). No entanto, o Código Criminal dizia, no artigo 12: "Os loucos que tiverem cometido crimes serão recolhidos às casas para eles destinadas, ou entregues às suas famílias, como ao juiz parecer mais conveniente." Embora à loucura não fosse dado nenhum tratamento específico, os loucos eram tratados diferentemente, segundo sua situação social. Eram os loucos pobres que vagavam pelas ruas oferecendo perigo às pessoas, como nos disse Sigaud (1835, apud Machado et alii, 1978) que a polícia médica deveria controlar e encaminhar às cadeias e à Santa Casa. O Código Criminal do Império mantinha em lei essa tradição.

Em 1852, o asilo foi inaugurado no Rio de Janeiro (Amarante, 1994). No entanto, a estratégia alienista permaneceu durante muitos anos sem uma lei que a legitimasse e os médicos queriam aumentar seu poder de 
intervenção, através da regularização dos termos da admissão dos enfermos aos asilos. Em 1886, Teixeira Brandão teceu críticas ao Código Criminal do Império, por considerar suas disposições parciais, imperfeitas e inobservadas (Machado et alii, 1978, pp. 481, 482). Argumentava o alienista que o nosso código era falho, por só contemplar o ato criminoso do alienado, "(deixando) de lado uma população louca que não cometeu crime"; por não prever um lugar para o perito-psiquiatra, para avaliação do estado mental do criminoso, o que dava ao juiz um poder excessivo; e por não existirem locais específicos para os loucos-criminosos. Teixeira Brandão já lutava pela construção do manicômio criminal e pela regulamentação da psiquiatria como especialidade médica.

\section{A completa privação dos sentidos e da inteligência}

O Código Criminal do Império, após a abolição, viria a ser reformado com base no projeto de João Batista Pereira, convertido em lei em 11 de outubro de 1890. O primeiro Código Penal da República trouxe mudanças significativas no estatuto jurídico penal do doente mental e seu destino institucional. Essas modificações podem ser apreendidas analisando-se em conjunto os artigos 1, 7, 27 e 29:

Art 1. Ninguém poderá ser punido por fato que não tenha sido qualificado crime, nem com penas que não estejam previamente estabelecidas.

Art 7. Crime é violação imputável e culposa da lei penal.

Art 27. Não são criminosos:

33. os que, por imbecilidade nativa, ou enfraquecimento senil, forem absolutamente incapazes de imputação;

\4. os que se acharem em estado de completa privação de sentidos e de inteligência no ato de cometer o crime.

Art 29. Os indivíduos isentos de culpabilidade em resultado de afecção mental serão entregues às suas famílias, ou recolhidos a hospitais de alienados, se o seu estado mental assim o exigir para a segurança do público.

O crime, não mais apenas um ato previsto em lei, recebe um novo atributo que se relaciona à imputabilidade do agente que o pratica. Assim, os loucos, sendo considerados inimputáveis, não têm o seu ato qualificado como crime. Mais do que isso, estava ausente também o estatuto de criminoso. O novo código especificava ainda o local para onde esses doentes deveriam ser encaminhados: o Hospício de Alienados. Completamente fora do âmbito da sanção penal, era a estratégia alienista que deveria dar conta de seu destino. A este respeito nos diz Drummond (s. d., pp. 99-100): "na defesa da ordem jurídica, 
contra o delito, toda a nossa complicada legislação penal não pode ir além, não pode alcançar mais do que isto: punir as ações imputáveis e culposas ... . Uma tal situação é de consumado 'abandono legal' da ordem jurídica."

Escorel (1905, p. 49), em seu comentário ao Código Penal, chama atenção para a distinção entre imputabilidade e responsabilidade, que em muitos casos são confundidas. Imputar, nos diz o jurista, "significa atribuir a um sujeito como causa, uma ação, um fenômeno, como efeito ... Imputabilidade (é) uma qualidade que tem em si uma ação ou um fenômeno qualquer que o torna atribuível àquela causa." A imputação, ou imputabilidade, estabelece uma relação causal entre um sujeito e uma ação, no caso, uma ação delituosa. A responsabilidade, por outro lado, relaciona-se às conseqüências legais do ato praticado. Os loucos, compreendidos no parágrafo 4 do artigo 27 entram, então, no campo da inimputabilidade: os atos por eles praticados não thes são atribuídos. Além disso, irresponsáveis que são, não respondem legalmente pelos atos cometidos; a eles não cabem as sanções penais.

Naquela época, a estratégia alienista já vinha ocupando o lugar que lhe cabia no controle social, e isto se deu em torno da questão dos loucos perigosos, mais especificamente dos monomaníacos (Castel, 1978; Machado et alii, 1978; Foucault, 1991, 1990). A loucura já não era mais compreendida como um fenômeno meramente intelectivo, mas como um fenômeno moral. O delírio não servia mais como delimitador do estado patológico. As paixões e a vontade lesadas davam lugar ao surgimento de uma loucura-lúcida que não era facilmente reconhecida e, por isso mesmo, ameaçava os juristas nos tribunais (Castel, 1978; Machado et alii, 1978; Carrara, 1998). Os "loucos de todo gênero" pareciam, dessa forma, uma categoria muito ampla que precisava ser delimitada. É o que dizem as palavras de Batista Pereira, relativas à fórmula por ele utilizada, a da "completa privação dos sentidos e da inteligência": "a intensidade da perturbação deve ser completa e não qualquer, porque só aquela tira ao indivíduo a consciência do ato ou a liberdade da determinação" (Escorel, 1905, p. 120). Ainda a esse respeito, nos diz Costa e Silva (1930, p. 189), o legislador teria optado pela completa privação, por estar "receoso de dar ao dispositivo uma amplitude inconveniente e perigosa". No entanto, se o que estava por trás dessa formulação era uma tentativa de delimitação da noção de loucura e conseqüentemente do espaço de atuação do alienismo, o efeito parece ter sido contrário. Mais do que isso, o artigo 27 foi um dos mais severamente criticados.

Inicialmente, e de forma bastante curiosa, o parágrafo 4 foi visto pelos juristas como um impeditivo a absolver os alienados delinqüentes. Muitos consideravam que "o estado de completa privação dos sentidos e da inteligência era incompatível com a atividade física e psíquica anormal necessária para que houvesse um ato... a tese só compreendia o cadáver, o corpo inerte e sem vida, incapaz de gesto ou ato... os 
tribunais e os juízes seriam forçados a condenar todos os loucos que não padecessem de imbecilidade nativa ou enfraquecimento senil, pois o parágrafo 4 do artigo 27 não podia ter aplicação a espécie alguma de loucura" (Costa e Silva, 1930, pp. 189- 90).

A princípio estreito, o artigo 27 vai tornando-se elástico demais aos olhos dos juristas e isto pelo fato de que em sua aplicação ele não poderia ser "interpretado materialmente, a fim de evitar o absurdo supranotado ... o código não se limitou ao conceito geral de loucura ... foi além e decretou, por uma tese muito mais vasta a irresponsabilidade criminal de todos aqueles que no ato de praticarem o crime não tenham a possibilidade de obrar livremente" (Soares, s. d., p. 76). Dessa forma, o código compreenderia, além dos loucos de todo gênero, os casos de sonambulismo, epilepsia, delírio febril, hipnose e embriaguez completa (Faria, 1929, p. 89; Soares, s. d., p. 78). O parágrafo 4 do artigo 27 , em realidade, referia-se a um "estado de inconsciência, seja qual for a causa" (Pereira, 1899, p. 16, apud Soares, s. d, p. 77).

O artigo então, assim interpretado pelos juristas, deu margem à ocorrência do efeito oposto ao desejado por Batista Pereira: ao invés de limitar, ampliou a noção de loucura e a penetração dos peritos psiquiátricos nos tribunais. A esse respeito, dizia-nos Escorel, em 1905 (p. 122): "Compete à medicina averiguar o fato da alienação mental, razão por que em todos os casos patológicos os exames médicos são as provas reconhecidas como as mais legítimas e precedentes." Devia-se, inclusive, dar aos peritos prazo suficiente para que pudessem chegar a alguma conclusão quanto ao estado mental do delinqüente. Esse procedimento, entretanto, mostrava-se insatisfatório na prática, aos olhos dos magistrados, uma vez que começaram a ocorrer "absolvições as mais vergonhosas" (Soares, s. d., p. 78). É o que nos dizem Costa e Silva (1930, p. 191) e Drummond (s. d., p. 101), respectivamente:

No Brasil inteiro, crimes indefensáveis, reveladores de requintada perversidade, lograram ficar impunes sob o errôneo e escandaloso fundamento da completa privação de sentidos e de inteligência.

...amplíssima porta escancaradamente aberta às mais escandalosas absolvições, constituiu-se o maior incentivo, a mais tentadora incitação à prática de todos os delitos ... Por essa brecha larguíssima, têm passado, e têm sido restituídos 'livres de culpa e pena', à plena fruição de 'seu direito de delinqüir', os piores, os mais perigosos perturbadores da ordem jurídica. Sob a nefasta proteção desse dispositivo do código penal.

Os limites teriam que ser estabelecidos, tanto da loucura, quanto do papel do perito. A perícia, prova mais significativa de alienação mental, passa a ser uma parte do processo que tem por fim último assessorar o juiz. Este poderia, até mesmo, discordar do exame e colocar o réu 
considerado irresponsável pela perícia em observação, para uma decisão posterior, "atenta sua análise científica": "A missão do perito é, apenas, esclarecer o juiz para que este possa bem aplicar a lei ... não lhe é lícito, abdicando a faculdade de julgar e de punir, submeterse cegamente ao parecer dos peritos" (Gama, 1929, p. 43).

Ainda com relação ao presente Código Penal, o parágrafo 3 do artigo 27 e a especificação da imbecilidade nativa também foram fonte de críticas: algumas no sentido de que, por ser uma espécie de alienação mental, deveria estar compreendida no parágrafo 4 (Soares, s. d., p. 75), outras, por não contemplar o presente parágrafo a imbecilidade adquirida (Costa e Silva, 1930, p. 186) e ainda por deixar espaço aberto para a existência de imbecis imputáveis, o que era contrário ao conhecimento científico da época (Soares, s. d., p. 75). E qual era esse conhecimento científico evocado pelos juristas nesse parágrafo? Com base nos comentadores do código, podemos perceber que a teoria da degenerescência de Morel vinha justificar suas críticas e argumentações: a imbecilidade, estado revelador de uma profunda degenerescência psíquica, expressava uma mentalidade que não tinha atingido seu pleno desenvolvimento, em decorrência de causas hereditárias perturbadoras. Além disso, apresentavam os imbecis como perigosos, selvagens e portadores de estigmas físicos. Nos imbecis, "Os sentimentos afetivos são rudimentares, existem como num estado de esboço selvagem. Os seus instintos e inclinações são de uma brutalidade chocante ... . Sob o impulso cego e irresistível de tendência cuja íntima gênese não pode conhecer-se, entregam-se muitas vezes ao furto, ao homicídio" (Mattos apud Soares, s. d., p. 75).

Embora já estivesse em curso o movimento dos alienistas pela construção de manicômios criminais, o Código Penal deixava claro que o local dos loucos-criminosos era o Asilo de Alienados (artigo 20). Muitos médicos posicionavam-se contra essa solução por considerá-la perigosa para a estratégia que se vinha conformando. Esse dispositivo dava margem à invasão dos asilos por criminosos, que comprometiam o tratamento e ameaçavam a especificidade da psiquiatria (Carrara, 1998): a internação de um alienado, questão científica, não poderia ser decidida por um juiz. Os juristas, no entanto, colocavam essa questão em outros termos, sequer considerando a possibilidade de deixar a cargo dos alienistas a decisão de internar ou não tais doentes-criminosos. Cabia definir se o juiz criminal, o juiz civil ou a autoridade policial ficariam responsáveis por esse procedimento, e as opiniões eram divergentes. Para Bento de Faria (1929, p. 100), o alienado criminoso, após considerado irresponsável, deveria ser encaminhado ao juiz civil para que se procedesse ao processo de interdição ou, de preferência, ao chefe de polícia: "A providência do artigo supra nada tem de repressiva; é ao contrário preventiva, e a polícia preventiva jamais foi exercida pelo presidente do júri." Por outro lado, dizia-nos Costa e Silva (1930, p. 227): "O fundamento da internação é a periculosidade 
do indivíduo. Essa periculosidade só pode ser reconhecida pelo juiz do crime."

O procedimento do artigo 29 é definido como uma medida preventiva, e a periculosidade aparece como um elemento jurídico, que só podia ser avaliada pelo juiz criminal. Começavam a surgir afirmações que demonstravam certa influência da antropologia criminal e escola penal positiva, fundadas por Lombroso: a periculosidade enquanto elemento central para definição da pena e a idéia da prevenção criminal (Carrara, 1998). Drummond (s. d., p. 127) mostrou-se um dos grandes defensores dessas idéias, propondo que fosse feita uma distinção entre responsabilidade moral e penal, uma vez que "precisamente indivíduos sem imputabilidade moral são os autores dos mais graves e mais alarmantes atentados contra a tranqüilidade social. Há mais ainda: os crimes mais aberrantes dos sentimentos de piedade e de moralidade trazem na sua própria monstruosidade o sinal evidente de inimputabilidade moral dos seus autores."

Os loucos, inimputáveis morais, eram os mais perigosos. Por isso, a imputabilidade penal deveria levar em consideração o grau de periculosidade do agente. Defendia ainda o jurista a individualização e indeterminação da pena, seguindo a idéia de punir o criminoso e não o crime: "A ação social punitiva há de, portanto, variar conforme a natureza dos atentados à ordem jurídica ... (e) na natureza do atentado, nada mais importante do que a feição subjetiva deste, isto é, (o) grau de anti-sociabilidade do autor" (Drummond, s. d., pp. 130, 249, 128). Para o doente, o "amental", o moralmente inimputável, defende a seqüestração definitiva, ad vitam. Esta justificava-se pela sua periculosidade máxima, que independia da gravidade do crime, pois "(a periculosidade) ... mostra-se muitas vezes maior em crimes objetivamente menores". Por conseguinte, os loucos, inimputáveis morais sem liberdade de autodeterminação, deveriam ser submetidos às sanções mais severas, num sentido oposto ao previsto no código de 1890, com "a aplicação da mais longa segregação, não raro, exatamente aos indivíduos de menor imputabilidade moral".

\section{A incapacidade de entendimento e determinação}

Uma série de projetos foi realizada para modificar o código até então vigente e adequá-lo aos avanços da ciência penal: o código brasileiro deveria acompanhar os avanços da criminologia (Schwarcz, 1995; Salla, 1999). Em 1893, o primeiro projeto de reformulação foi entregue à Câmara dos Deputados pelo deputado Vieira de Araújo, seguindo-se vários outros: o da Comissão Especial da Câmara, o projeto Galdino Siqueira (1913), o projeto Sá Pereira (1935) e o projeto Alcântara Machado (1938) (Oliveira e Silva, 1942, p. 89). Este foi submetido a uma comissão revisora, cujo trabalho resultou no projeto que foi convertido em lei, em 1940, na vigência do Estado Novo (Brasil, decreto-lei 2.848/40). 
A definição de crime volta a ser independente da imputabilidade do delinqüente e o doente mental não deixa de ser criminoso em decorrência de seu estado, o que é definido nos artigos 1 e 22:

Art 1. Não há crime sem lei anterior que o defina. Não há pena sem prévia cominação legal.

Art 22. É isento de pena o agente que, por doença mental, ou desenvolvimento mental incompleto ou retardado, era, ao tempo da ação ou da omissão, inteiramente incapaz de entender o caráter criminoso do fato ou de determinar-se de acordo com o entendimento.

Parágrafo único: A pena pode ser diminuída de $1 / 3$ a $2 / 3$, se o agente, em virtude de perturbação da saúde mental ou por desenvolvimento mental incompleto ou retardado, não possuía ao tempo da ação ou da omissão, a plena capacidade de entender o caráter criminoso do fato ou de determinar-se de acordo com esse entendimento.

Ao contrário do que foi proposto por Magalhães Drummond, o código de 1940 não adotou a distinção entre imputabilidade moral e penal. A responsabilidade penal continuava fundada na responsabilidade moral, com base na doutrina do livre-arbítrio. A princípio, percebemos certa incoerência nos procedimentos adotados no novo código, que, se por um lado pautava-se na doutrina clássica e aceitava o pressuposto da vontade livre, por outro, pautava-se nas idéias da escola positiva e concebia, em casos de loucura, por exemplo, o crime como determinado por causas biológicas que comprometiam a vontade e o entendimento. A esse respeito nos diz o ministro Francisco Campos, em sua exposição de motivos: "O projeto não reza em cartilhas ortodoxas, nem assume compromissos irretratáveis ou incondicionais com qualquer das escolas ... inclina-se para uma política de transição ou conciliação" (apud Oliveira e Silva, 1942, p. 91).

A doença mental nesse novo código - compreendida não mais apenas como uma lesão do entendimento — não é determinante absoluta da inimputabilidade. Para a determinação da imputabilidade do criminoso, adotava o novo código o critério biopsicológico, numa tentativa de evitar, "no combate ao crime, o arbítrio do médico e o do juiz" (idem, ibidem, p. 12). O critério adotado em nosso código concebe o crime como contendo um momento intelectivo, que se relaciona com a capacidade de entendimento, e um momento volitivo, relacionado com a capacidade de determinação. Para caracterizar um criminoso como inimputável, segundo Jesus (1988, p. 444), é suficiente a ausência de um dos elementos - a vontade ou o entendimento —- em decorrência de doença mental ou desenvolvimento mental incompleto ou retardado. O critério biopsicológico, segundo Hungria e Fragoso (1978, pp. 324-5), avalia a existência de um nexo de causalidade entre o estado mental 
patológico e o crime, e pressupõe que "não há uma relação necessária e constante entre o pathos mental do agente e a sua conduta criminosa". Para que o doente mental seja considerado irresponsável, deve-se levar em consideração "o período ou grau de evolução da doença ou deficiência mental, da estrutura psíquica do indivíduo e da natureza do crime".

Para o código de 1940, são as "causas biológicas" as únicas capazes de suprimir a capacidade de entendimento e determinação, quando deixa de existir a responsabilidade (Hungria e Fragoso, op. cit., pp. 322, 331). Ao perito cabe auxiliar o juiz sempre que haja suspeita de insanidade mental, avaliando se havia, no momento do crime, supressão do entendimento ou da vontade, em decorrência de doença mental ou desenvolvimento mental retardado; ao juiz, caberá sempre a "última palavra', com sua prerrogativa de livre convencimento".

A inimputabilidade relaciona-se diretamente com a culpabilidade do delinqüente, a qual, definida como "o aspecto subjetivo do delito que concerne a intenção de delinqüir" (Moura, 1996, p. 89), funciona como condição para imposição da pena. Com base no artigo 22, podemos ver que os doentes mentais são isentos de pena e, por isso, a doença mental no código de 1940 é considerada como uma causa de exclusão da culpabilidade: o crime existe, mas não é efetivo em relação ao sujeito. Se está ausente a culpabilidade - elemento que liga o agente ao crime - isso determina a inimputabilidade, de modo que não pode ser juridicamente imputada a prática de um fato punível ao sujeito (Jesus, 1988, p. 397). A responsabilidade penal, por sua vez, relaciona-se com as conseqüências jurídicas decorrentes do ato criminoso — "é a obrigação de sofrer o castigo, ou incorrer nas sanções penais impostas ao agente do fato ou omissão criminosa" (Chaloub, 1981, p. 83) - e, para que haja responsabilidade, é necessário a existência de imputabilidade.

Cabe aqui levantarmos uma questão: se os doentes mentais são isentos de culpabilidade, inimputáveis e irresponsáveis, estão fora do âmbito das sanções penais? A princípio, poderia nos parecer que sim. No entanto, esse novo código trouxe ainda uma nova modalidade de ação penal, na forma de medida de segurança. Vejamos o código:

Art. 76. A aplicação da medida de segurança pressupõe:

I - a prática do fato previsto como crime;

II — a periculosidade do agente.

Art. 77. Quando a periculosidade não é presumida por lei, deve ser reconhecido perigoso o indivíduo, se a sua personalidade e antecedentes, bem como os motivos e circunstâncias do crime autorizam a suposição que venha ou torne a delinqüir. 
Art. 78. Presumem-se perigosos:

I - aqueles que, nos termos do art. 22, são isentos de pena;

II — os referidos no parágrafo único do artigo 22.

As medidas de segurança surgem para possibilitar ao direito penal um espaço de atuação frente aos irresponsáveis e "semi-responsáveis", que, com base no código anterior, estavam fora do âmbito das sanções penais. Segundo o ministro Francisco Campos (apud Oliveira e Silva, 1942, p. 92), as medidas de segurança vieram corrigir a anomalia presente no código de 1890, que, ao isentar de pena os doentes mentais perigosos, não previa para eles nenhuma medida de segurança ou de custódia, deixando-os completamente a cargo da Assistência a Alienados. Em que se constitui a medida de segurança? Em que diferem das penas? Por que e como são utilizadas no Brasil? Para responder a essas questões, vamos reportar-nos à sua formulação primeira que se encontra no centro do desenvolvimento da escola positiva de direito penal.

As idéias de Lombroso buscavam uma reformulação geral da doutrina do direito. Dentro desse contexto, surge uma nova lógica da sanção penal, pautada nos postulados positivistas do biodeterminismo e da existência de leis universais de causalidade (Harris, 1993; Carrara, 1998). A pena deveria perder seu caráter punitivo, passando a ser uma medida de defesa social e de prevenção criminal, indeterminada em sua duração. A pena, não mais castigo, deveria ser determinada com base na periculosidade do indivíduo, a qual seria avaliada através do exame de sua personalidade. O critério da periculosidade subjetiva viria fundamentar a ação preventiva do Estado (Hungria e Fragoso, 1978, p. 21) ao recusar as idéias de vontade livre, responsabilidade moral e caráter retributivo da pena. O crime, entendido como um produto da ação de fatores endógenos e exógenos sobre a vontade, pediria não mais medidas aflitivas, mas profiláticas ou de defesa proporcionais ao perigo representado pelo indivíduo. Os juristas, adeptos da escola clássica, rejeitaram essas idéias por se mostrarem incompatíveis com o direito de punir, uma vez que eram contrárias à doutrina do livrearbítrio. Além disso, a idéia de indeterminação da pena deixava espaço para arbitrariedades por parte do poder judiciário. No entanto, em uma classe especial de criminosos, os criminosos-loucos e os "semiresponsáveis", tiveram aplicação na forma da medida de segurança, permitindo que o direito penal controlasse seus atos.

As medidas de segurança surgem no Código Penal brasileiro como medidas especiais para criminosos específicos: os doentes mentais perigosos. Segundo o ministro Francisco Campos (apud Oliveira e Silva, 1942, p. 92), as medidas de segurança diferem das penas, que são repressivas e intimidantes, por serem de finalidade preventiva, "embora aplicáveis em regra post delictum". A pena, para o ministro, embora individualizada em sua aplicação, difere ainda da medida de segurança, 
uma vez que, para essa, é conferida ao juiz a "liberdade em tudo quanto se refere à aplicação e à execução", devendo-se apenas respeitar o limite mínimo de sua duração. A indeterminação, nesse caso, é considerada em sua totalidade, não existindo um limite máximo de duração a ser respeitado: "Por sua própria natureza e fim, a medida de segurança individual é imposta por tempo indeterminado, isto é, até que cesse o 'estado perigoso' do indivíduo a ela submetido."

Segundo Hungria e Fragoso (1978, pp. 11,13), pena e medida de segurança não diferem apenas por apresentarem finalidades distintas, repressiva ou preventiva, mas, também, pelas causas, condições de aplicação e modo de execução. A pena aplica-se, exclusivamente, aos responsáveis e funda-se na culpabilidade ou culpa moral do delinqüente. É, por isso, de cunho essencialmente ético e baseada na justiça. Além disso, é caracterizada como uma sanção imposta a um fato concreto e passado - o crime -, de forma retributiva, aflitiva e proporcional à gravidade. No entanto, a pena visa também promover prevenção geral e especial contra o crime. A medida de segurança, por sua vez, aplicase aos semi-responsáveis e irresponsáveis, tomando como fundamento não mais a culpabilidade mas a periculosidade, "o provável retorno à prática de fato previsto como crime". Caracterizada como "eticamente neutra" e fundamentada na sua utilidade, a medida de segurança serve ao fim de "segregação tutelar" ou de readaptação individual, sendo desprovida do caráter aflitivo da pena, pois "é assistência, é tratamento, é medicina, é pedagogia. Se acarreta algum sacrifício ou restrição à liberdade individual, não é isso um mal querido como tal ou um fim colimado, mas um meio indispensável à sua execução."

O crime funciona, para aplicação da medida de segurança, como um sintoma do estado perigoso individual. Como não é possível saber ao certo a duração desse "estado", a medida de segurança é indeterminada em sua duração. Nesse sentido, caracteriza-se como preventiva, voltada para a "neutralização profilática ou recuperação do indivíduo":

A pena olha, simultaneamente para o passado e para o futuro; a medida de segurança olha somente para o futuro. Para uma, o crime acontecido é fundamento necessário e suficiente; para outra, é apenas ocasião, pois seu fundamento transcende o crime, para legitimar-se com a periculosidade do seu autor. Para a incidência na pena, basta o crime, pois somente na medida de seu quantum é que se tem em conta a pessoa do criminoso. Para a medida de segurança, o crime é apenas um eventual sintoma ou indício de 'estado perigoso' individual que é a sua condição sine qua non.

Vejamos então como se caracteriza, no Brasil, o procedimento adotado com os doentes mentais delinqüentes: a doença mental no código de 1940 é causa excludente de culpabilidade e, por isso, os doentes mentais criminosos são absolvidos. Uma vez que são absolvidos 
e carentes de culpabilidade não devem ser punidos, mas tratados. Dessa forma, aplica-se a tais loucos-criminosos a medida de segurança com internação em manicômio judiciário, a qual funda-se em sua periculosidade presumida por lei (artigo 78, I). No entanto, chama-nos atenção Oliveira e Silva (1942, p. 12): "Poderá o internado concordar, perante a consciência, que não está 'preso', mas simplesmente 'detido', em virtude da decretação de medida de segurança... Convenhamos que será admitir, em tal indivíduo, a suprema sabedoria da resignação filosófica, em que não distinguirá, senão nebulosamente, a liberdade, da reclusão..." Para o jurista, tanto a pena como a medida de segurança visam corrigir, reeducar, transformar o indivíduo, curar, ajustá-lo à vida em sociedade. Ambas são aplicadas pelo juiz, como conseqüência de um ato criminoso, e ambas guardam relação com o grau de ameaça do delinqüente à ordem social; ambas visam "proteger" o indivíduo da vingança e prevenir a reincidência criminal. Conclui ainda, dizendonos: "Toda medida detentiva constitui privação de liberdade. Não nos embaracemos num verbalismo inútil, para distinguir, em relação aos movimentos do indivíduo, o que seja internação em casa de custódia, colônia agrícola ou instituto de trabalho da prisão carcerária ou da penitenciária."

A medida de segurança inaugura, no campo do direito penal, a possibilidade de atuação frente à loucura, uma atuação travestida de tratamento e, em discurso, desprovida de aflição. A medida de segurança não é pena, é tratamento, é assistência, argumentou o ministro em sua exposição de motivos. No entanto, mostra-se, como nos disse Fragoso, ainda mais aflitiva do que a pena por seu caráter indeterminado. A esse respeito, afirma Cohen (1996, p. 82): "No caso de seu enquadramento na medida de segurança, isto é, quando for considerado como perigoso socialmente, ele não saberá quanto tempo ficará recluso, pois isto depende da cessação de sua periculosidade, tornando-se em muitos casos, uma condenação de prisão perpétua."

Um ponto a ser considerado com relação à medida de segurança, no código de 1940, é seu caráter indeterminado, sendo fixo apenas o tempo mínimo. Este, em que pese a sua determinação com base na periculosidade, guarda estreita relação com o crime cometido. Nesse sentido, a internação no Manicômio Judiciário tem seus termos definidos no artigo 91:

Art. 91. O agente isento de pena, nos termos do artigo 22, é internado em manicômio judiciário.

\1. A duração da internação é, no mínimo:

I - de seis anos, se a lei comina ao crime pena de reclusão não inferior, no mínimo, a 12 anos;

II - de três anos, se a lei comina ao crime pena de reclusão não inferior, no mínimo, a oito anos; 
III — de dois anos, se a pena privativa de liberdade, cominada ao crime, é, no mínimo, de um ano;

IV — de um ano nos outros casos.

『2. Na hipótese do nº IV, o juiz pode submeter o indivíduo apenas a liberdade vigiada.

$₫ 4$. Cessa a internação por despacho do juiz, após perícia médica, ouvidos o Ministério Público e o diretor do estabelecimento.

§5. Durante um ano depois de cessada a internação, o indivíduo fica submetido a liberdade vigiada, devendo ser de novo internado se seu procedimento revela que persiste a periculosidade. Em caso contrário, encontra-se extinta a medida de segurança.

Alguns pontos mostram-se interessantes, no que se refere aos termos definidos anteriormente. Como dizem Hungria e Fragoso (1978, pp. 189, 190), o tempo mínimo fixado visa "proteger" o juiz de "influências espúrias" de "laudos superficiais ou conclusões prematuras". Hungria e Fragoso põem em evidência a permanência do conflito entre juristas e psiquiatras, os quais "estão sempre inclinados a conjecturas otimistas sobre a cessação de periculosidade dos pacientes". Acrescentam ainda que, em se tratando de doentes mentais, como definido no artigo 22 , essa possibilidade de revogação da medida em um curto tempo deveria ser "conjurada", uma vez que

somente depois de prolongado tratamento e detida observação médica pode um estado de profunda morbidez psíquica ser declarado curado (quando acessível à cura) ou suficientemente atenuado ... . A experiência tem demonstrado que, não obstante demorado tratamento e plausível indicação de cura, o liberado do manicômio não tarda, às vezes, em revelar a persistência de sua periculosidade, fazendo-se protagonista de crimes da maior gravidade. O prazo mínimo de internação é, aqui, um preservativo, até certo ponto eficaz, contra a precipitada antecipação de retorno do internado ao convívio social.

Fecha-se, então, em torno do doente mental, o "dispositivo de controle-dominação da loucura" (Foucault, 1995a, p. 244). Baseado no saber psiquiátrico e na justiça criminal, este dispositivo forma-se através de duas estratégias: a psiquiátrica, que privilegia a doença e parece não mais reconhecer a periculosidade sob a qual se constituiu; e a jurídicopenal, ou "estratégia da periculosidade". Esta estabelece-se como uma rede extremamente complexa, através da união dos dois campos de atuação: a psiquiatria e a justiça. Com uma lógica particular que se volta para o futuro e molda-se em torno de uma doença-perigo, ela absolve mas interna com o argumento da periculosidade. Dispositivo complexo, encontra como ponto inicial a constituição do alienismo, 
que, através de um saber sobre a loucura, caracteriza-a como irresponsável e perigosa, justificando sua estratégia de ação (Castel, 1991, 1978; Foucault, 1995, 1991, 1990). Agora, institucionalmente sustentada pela medida de segurança, a estratégia da periculosidade possibilita uma atuação formal do direito penal na loucura. A medida de segurança, de acordo com Hungria e Fragoso (1978, p. 24), é "uma ampliação, à órbita jurídico-penal, das providências de caráter administrativo que, já então, em vários países civilizados, se tomavam em relação aos loucos, aos ébrios habituais e aos menores delinqüentes".

Definida como probabilidade de delinqüir, a periculosidade surge no Código Penal de 1940 como o fundamento da medida de segurança, procedimento adotado com os doentes mentais delinqüentes. No entanto, o que nos parece é que, embora explicitamente vinculada a esse procedimento, a periculosidade se mostra como um conceito central para aplicação de sanção penal, apesar de Hungria e Fragoso (op. cit., pp. 27-8) afirmarem não ter ela qualquer relação com a pena: a periculosidade "não interfere com a pena, nem mesmo para sua fixação in concreto. É certo que os critérios de orientação na medida da pena são essencialmente os mesmos indicados para averiguação da periculosidade; mas, no cálculo da pena, o que se tem a investigar é a capacidade de delinqüir, que, se tem notas em comum com a periculosidade, não se confunde com esta."

Em que se diferenciam, então, periculosidade e capacidade de delinqüir? Esta questão mostra-se fundamental para compreendermos o dispositivo que se instaura em torno dos loucos-criminosos, que são paradoxalmente absolvidos e submetidos a uma sanção penal indeterminada em sua duração, justamente por ser tal procedimento fundamentado na periculosidade. A capacidade de delinqüir refere-se ao caso concreto, ao crime praticado e, para Hungria e Fragoso (idem, ibidem), limita-se a este enquanto um fato certo e passado. É utilizada pelo juiz como critério para individualização da pena dentro de um limite de duração, mínimo e máximo, previamente estabelecido. A periculosidade, por sua vez, relaciona-se com a conduta futura do delinqüente e, por isso mesmo, é uma probabilidade que o sujeito torne a delinqüir:

A periculosidade é uma prognose, um fato provável ... é o estado psíquico do agente como provável causa de novos crimes ... não serve a um objeto de justiça, mas de utilidade: não é fundamento à justa ou proporcionada retribuição do mal pelo mal, que o Estado, na sua função ética, se arroga, mas à atividade defensiva que o Estado tem o direito e o dever de exercer, em face da autorizada suposição de novos males por parte do indivíduo violador da lei.

No entanto, ambas, capacidade de delinqüir e periculosidade, são avaliadas em relação à personalidade do sujeito delinqüente, 
aos antecedentes, motivos determinantes do crime e sua gravidade objetiva e subjetiva (dolo ou culpa). Ambas transcendem a órbita do crime enquanto um fato concreto. A diferença é que a periculosidade, enquanto probabilidade, permite uma intervenção indeterminada. Devemos ainda levar em consideração que a periculosidade surge como elemento central do direito penal, com as idéias da escola positiva, segundo a qual toda e qualquer sanção penal deveria ser determinada com base nesse conceito, procedimento rejeitado no Brasil, mas não completamente.

Apesar de admitir explicitamente "que existe em todo homem um criminoso in potentia, cuja eclosão pode ser favorecida e não necessariamente determinada, por condições pessoais e sociais; ... (e que) a geral potencialidade para o crime não significa jamais proclividade inexorável ou predisposição fatal" (Hungria e Fragoso, op. cit., pp. 46, 49, 52), o nosso código adotou o chamado sistema enumerativo, pelo qual a periculosidade não é reconhecida de forma geral, como característica do gênero humano, mas de certas classes de delinqüentes, dentre os quais encontramos os "inferiorizados psíquicos", como vimos no artigo 78: "Não existe, repita-se, uma propensão irremediável para o crime. A não ser que se trate de um louco autêntico ... . Indivíduos irresponsáveis, cuja reação anti-social é sintoma ou reflexo de típica doença ou grave déficit mental, por isso que, faltando-lhes, totalmente, a capacidade de entendimento ético e de autogoverno, são de alta periculosidade."

Segundo Hungria e Fragoso (op. cit., p. 59), a personalidade do sujeito representa probabilidades de conduta, havendo sempre espaço para a liberdade e autodeterminação, mediadas pela vontade. Quando se orienta no sentido da criminalidade, encontramos a chamada periculosidade como expressão da personalidade. Como o nosso código de 1940 presumia em lei a periculosidade dos doentes mentais, a personalidade deles não precisava ser avaliada no processo penal, o que objetivamente retira dos doentes mentais o "espaço de liberdade" de suas condutas: têm, a princípio, periculosidade máxima, quase como um cálculo preciso e invariavelmente certo.

Em que se baseia essa presunção de periculosidade? Na relação de constância, na experiência, no hábito; na idéia de que "a prática de um primeiro crime afeiçoa o agente à prática de outro" (Hungria e Fragoso, op. cit., pp. 38, 39), principalmente quando presentes condições sociais e psíquicas: "em certos casos, a lei, tendo em conta a relação de constância entre o crime e determinadas condições (psíquicas ou sociais) do agente, presume juris et jure a periculosidade". Quando a periculosidade é presumida por lei, dispensa-se a prática do fato previsto como crime para aplicação da medida de segurança, sendo suficiente a ocorrência de um "quase-crime". O crime impossível e a tentativa inadequada, embora não sejam fatos criminosos, poderiam ser considerados indícios de periculosidade. 
Um outro ponto a ser considerado aqui, e que se refere ao juízo de periculosidade, é a relação entre personalidade, tipo e motivação do crime: o indivíduo é considerado mais perigoso, quanto mais o crime (tipo e motivo) corresponda à sua personalidade: "Quanto mais um crime corresponde à personalidade do agente, tanto maior é a periculosidade deste, isto é, tanto maior é a probabilidade de que torne a delinqüir. $O$ crime que não se enquadra na personalidade de seu autor é, em relação a este, um episódio acidental ou com muito pouca probabilidade de presunção" (idem, ibidem, p. 54).

E o que ocorre no caso do doente mental? A partir da discussão sobre a monomania no século XIX, os psiquiatras foram chamados a atuar nos tribunais, justamente nos casos de crimes ilógicos, irracionais, inesperados, acidentais e sem motivo. Isso, para Foucault (1991a, 1990, pp. 245, 236), colocava os juízes diante de um grande problema, o qual deve ser compreendido dentro das modificações que vinha sofrendo o direito penal. Segundo Foucault, a questão que se impõe aos tribunais na atualidade refere-se ao sujeito delinqüente, e não mais ao crime como fato concreto. Essa questão começou a se impor aos juízes no século XIX, com a intervenção da psiquiatria nos tribunais, em torno dos crimes sem razão, "os crimes que não são precedidos, acompanhados ou seguidos de nenhum dos sintomas tradicionalmente reconhecidos e visíveis da loucura". Além disso, eram crimes graves, ocorridos na esfera doméstica e, o mais importante, eram crimes sem motivo. A motivação para o ato delinqüente ganha, a partir de então, um lugar de destaque na atividade de julgar. Em fins do século XVIII e início do século XIX, ocorreu um deslocamento no campo jurídico-penal, passando a ser o criminoso o objeto da punição. Dessa forma, o crime se articula à personalidade do sujeito delinqüente e desta articulação depende o sucesso do sistema punitivo; nela se baseia sua lógica. O castigo, em sua forma privativa de liberdade, que tem por fim último recuperar os delinqüentes, volta-se contra seus motivos, vontade, tendências e instintos.

A doença, sob a forma da monomania, toma o lugar do motivo ausente. O ato inesperado, ilógico e inexplicável articula-se à conduta global do sujeito pela doença que o determinou (Foucault, 1990). Se a periculosidade é máxima, quanto mais lógico se mostre o crime, como nos disseram Hungria e Fragoso, a ilogicidade da loucura a excluiria do rol dos perigosos. No entanto, presume-a em lei o nosso código, tornando dispensável a avaliação da personalidade e sua articulação com o ato.

Ainda um ponto a ser considerado, com relação ao nosso Código Penal de 1940, é que o juízo de periculosidade deveria ser feito pelo juiz, e não por psiquiatras e psicólogos, in concreto (Hungria e Fragoso, 1978, pp. 56, 86-7), através da análise da história de vida do réu: "sua história desde a infância, no lar, na escola, no grupo social a que pertence, no meio ambiente em que viveu, na oficina, na caserna, no 
${ }^{1}$ É importante ressaltar que está em tramitação uma nova reforma do código penal, em sua parte geral. convívio social em geral, nos seus meios de vida, na suas formas de conduta, nos seus modos de reação. Só então será viável a concatenação de dados que possam deixar entrever, menos inseguramente, a intimidade psíquica do homem que se vai julgar." Eis que surge no direito penal brasileiro o novo objeto da punição, o "homem que se vai julgar". Nos casos de loucura, esse homem é, de antemão, conhecido; não é necessário ao juiz vasculhar seu passado, desvendar suas relações, decifrar suas condutas para aplicar-lhe a sanção penal. A doença já o mostra em sua personalidade criminal, em sua máxima periculosidade e, para reconhecê-la, a psiquiatria é chamada através da perícia, ou exame de sanidade mental.

O Código Penal vigente é ainda o de 1940, ao qual foram feitas algumas alterações através da Lei de Execuções Penais 7.209/84. ${ }^{1}$ No entanto, ainda permanece a mesma diretriz no que se refere à atuação frente ao doente mental delinqüente. Não vamos aqui reproduzir o que se manteve, ou seja, a inimputabilidade e irresponsabilidade do doente mental e a semi-responsabilidade dos que apresentam "perturbação da saúde mental" se encontram nos mesmos termos, agora no artigo 26. Algumas modificações, no entanto, foram feitas com relação às medidas de segurança:

Art. 96. As medidas de segurança são:

I - Internação em hospital de custódia e tratamento ou, à falta, em outro estabelecimento adequado.

II — Sujeição a tratamento ambulatorial.

Art. 97. Se o agente for inimputável, o juiz determinará a sua internação. Se todavia o fato previsto como crime for punível com detenção, poderá o juiz submetê-lo a tratamento ambulatorial.

\$1. A internação, ou o tratamento ambulatorial, será por tempo indeterminado, perdurando enquanto não for averiguada, mediante perícia médica, a cessação de periculosidade. O prazo mínimo fixado deverá ser de um a três anos.

\$2. A perícia médica realizar-se-á ao termo do prazo mínimo fixado e deverá ser repetida de ano em ano, ou a qualquer tempo, se o determinar o juiz da execução.

\$3. A desinternação, ou a liberação, será sempre condicional devendo ser restabelecida a situação anterior se o agente, antes do decurso de um ano, pratica fato indicativo de sua periculosidade.

\$4. Em qualquer fase do tratamento ambulatorial, poderá o juiz determinar a internação do agente, se essa providência for necessária para fins curativos. 
A medida de segurança se apresenta, agora, sob a forma de internamento em hospital de custódia e tratamento ou similiar e o tratamento ambulatorial. Além disso, o prazo mínimo de duração deve ser determinado pelo juiz, no limite mais estreito de um a três anos, mantendo-se, no entanto, o seu caráter indeterminado e a liberdade condicional que a segue. Os limites continuam elásticos, a lógica mantémse: o doente mental delinqüente é englobado por uma estratégia que se centra na periculosidade — futuro, risco, probabilidade —, à qual cabe uma sanção indeterminada.

\section{Conclusão}

Segundo Adorno (1991, pp. 66-7), as políticas públicas penais brasileiras apresentam uma orientação eclética representada pelos diferentes procedimentos adotados, no que se refere a uma sanção contra o crime e contra o criminoso. Ou seja, "algumas políticas penais enfatizam a repressão do ato em si, definido na letra da lei como crime ou contravenção penal, ao passo que outras priorizam o comportamento dos agentes, tentando intervir em seu suposto potencial "criminógeno". A partir da análise dos códigos penais brasileiros, percebemos que ao ecletismo identificado por Adorno acrescenta-se a "estratégia da periculosidade". O louco-criminoso e o seu lugar institucional - o manicômio judiciário ou hospital de custódia e tratamento - estão ambos dentro do contexto das políticas criminais, fazem parte do sistema penitenciário. A periculosidade — que, como vimos, difere do "potencial criminógeno" ou capacidade de delinqüir — soma-se a este ecletismo, dando margem a uma terceira vertente nas políticas penais brasileiras, cuja sanção característica não é a pena privativa de liberdade, mas a medida de segurança, procedimento indeterminado e que se diz preventivo. O doente mental, no Brasil, tem o seu estatuto jurídico marcado pela ambigüidade: a sua doença é o móvel de seu ato, excluindo por isso a culpabilidade e a responsabilidade. $\mathrm{Na}$ "estratégia da periculosidade", a punição justifica-se como tratamento, e a prevenção fundamenta-se em um ato passado.

Para concluir, mais um ponto merece ser comentado com relação ao dispositivo jurídico da loucura-perigo no Brasil. Vimos que aos doentes mentais são reservadas as medidas de segurança que se fundamentam na periculosidade, ou seja, em probabilidade, suposição, hábito. "A justiça penal tem de contentar-se, aqui, com indícios, com sinais, ou sintomas, ou cálculos aproximativos para averiguar o conjunto de probabilidades, que é, afinal de contas, a personalidade individual" (Hungria e Fragoso, 1978, p. 85). A periculosidade é um risco e, por isso, uma incerteza que se expressará, talvez, num futuro também incerto. Frágil mostra-se para nós o fundamento da medida de segurança. No entanto, e aqui encontramos mais um ponto característico da política penal da loucura, tantas incertezas não se mostram problemáticas, uma 
vez que a medida de segurança não é uma pena. Para que ela seja aplicada, é suficiente a "razoável suspeita" ou a "fundada suposição" e, em se tratando de perigosos, não se aplica o clássico critério de solução da justiça in dubio pro reo, mas sim o in dubio pro republica.

\section{REFERÊNCIAS BIBLIOGRÁFICAS}

Adorno, Sérgio

1991

Amarante, Paulo (org.) 1994

Oliveira Silva (org.) 1942

Brazil 1876

Carrara, Sergio 1998

Castel, Robert 1991

Castel, Robert 1978

Chaloub, Miguel 1981

Cohen, Cláudio 1996

Corrêa, Mariza 1998

Costa e Silva, José da 1930

Cunha, Maria

Clementina Pereira 1986

Delmanto, Celso 1991

Drummond, Magalhães s. d.

Engel, Magali Gouveia nov. 1998-fev. 1999

Escorel, Manoel

Clementino de Oliveira 1905

Faria, Antônio Bento de 1929
'Sistema penitenciário no Brasil: problemas e desafios'. Revista USP, 9, pp. 65-78.

'Asilos, alienados e alienistas: uma pequena história da psiquiatria no Brasil'. Em Psiquiatria social e reforma psiquiátrica. Rio de Janeiro, Fiocruz, pp. 73-84.

'Exposição de motivos do ministro Francisco Campos ao presidente da República, referente ao novo Código Penal' (decreto-lei no 2.848, de 7 de dezembro de 1940). Em Inovações do Novo Código Penal. Rio de Janeiro, Alba.

'Código Criminal do Império'. Anotado por Araújo Filgueiras Júnior. Rio de Janeiro, Casa de editores proprietários Eduardo e Henrique Laemmert.

'Crime e loucura: o aparecimento do manicômio judiciário na passagem do século'. Rio de Janeiro/São Paulo, Eduerj/Edusp.

'Os médicos e os juízes'. Em Michel Foucault, Eu, Pierre Rivière, que degolei minha mãe, minha irmã e meu irmão... um caso de parricídio do século XIX. Rio de Janeiro, Graal, pp. 259-75.

A ordem psiquiátrica: a idade de ouro do alienismo. Rio de Janeiro, Graal.

Introdução à psicopatologia. Rio de Janeiro, Forense.

'Medida de segurança'. Em Claudio Cohen, Flavio Carvalho Ferraz e Marco Segre (orgs.), Saúde mental, crime e justiça. São Paulo, Edusp, pp. 77-86.

As iIusões da liberdade: a escola Nina Rodrigues e a antropologia no Brasil. Bragança Paulista, Edusf.

Código Penal dos Estados Unidos do Brasil.

São Paulo, Companhia Editora Nacional.

O espelho do mundo: Juquery, a história de um asilo. Rio de Janeiro, Paz e Terra.

Código Penal comentado. São Paulo, Renovar.

Aspectos do problema penal brasileiro. Rio de Janeiro, Oficinas Gráficas Sfredo \& Gravina.

'As fronteiras da anormalidade: psiquiatria e controle social'. História, Ciências, Saúde - Manguinhos, V(3), pp. 547-63.

Codigo Penal Brazileiro.

São Paulo, Duprat e comp., vol. I.

Annotacôes theorico-práticas ao Código Penal do Brasil. Rio de Janeiro, Jacintho Ribeiro dos Santos Ed., vol. I. 
Filgueiras-Jr. Araújo

1876

Foucault, Michel

1995

Foucault, Michel

1995a

Foucault, Michel

1991

Foucault, Michel

1991a

Foucault, Michel

1990

Fry, Peter

Fry, Peter

1982

Gama, Affonso Dionísio

1929

Harris, Ruth

1993

Hungria, Nelson e

Fragoso, Heleno

1978

Jesus, Damásio E. de 1988

Machado, Roberto et alii 1979

Mattos, Júlio de s. d.

Moura, Luiz Antonio 1996

Noronha, E. Magalhães 1990

Oliveira e Silva

1942

Salla, Fernando

1999

Schwarcz, Lilia Moritz 1995

Soares, Oscar

de Macêdo

s. d.
Código criminal do Império do Brazil.

Rio de Janeiro, Casa dos editores proprietários Eduardo \& Henrique Laemmert.

História da loucura.

São Paulo, Perspectiva.

Microfisica do poder.

Rio de Janeiro, Graal.

Eu, Pierre Rivière, que degolei minha mãe, minha irmã e meu irmão... Um caso de parricídio do século XIX. Rio de Janeiro, Graal.

Vigiar e punir: história da violência nas prisões.

Petrópolis, Vozes.

'La evolución de la noción de individuo peligroso en la psiquiatría legal'.

Em La vida de los hombres infames: ensayos sobre desviación y dominación. Madri, La Piqueta, pp. 231-64.

'Direito positivo versus direito clássico: a psicologização do crime no Brasil no pensamento de Heitor Carrilho'. Em Sérvulo A. Figueira (org.), Cultura da psicanálise. São Paulo, Brasiliense, pp. 116-42.

'Febrônio Índio do Brasil: onde cruzam a psiquiatria, a profecia, a homossexualidade e a lei'. Em Alexandre Eulálio et al., Caminhos cruzados: linguagem, antropologia e ciências naturais. São Paulo, Brasiliense, pp. 65-80.

Código Penal Brasileiro.

São Paulo, Saraiva e C. Editores.

Assassinato e loucura: medicina, leis e sociedade no fin de siècle.

Rio de Janeiro, Rocco.

Comentários ao Código Penal.

Rio de Janeiro, Forense.

Direito Penal.

São Paulo, Saraiva.

Danação da norma: medicina social e constituição da psiquiatria no Brasil. Rio de Janeiro, Graal.

Manual das doenças mentaes. Em Oscar Macêdo Soares, Código Penal da República dos Estados Unidos do Brasil. 5ํㅡㄹ. ed., Rio de Janeiro, Livraria Garnier.

'Imputabilidade, semi-imputabilidade e inimputabilidade'. Em Claudio Cohen, Flavio Carvalho Ferraz e Marco Segre (orgs.), Saúde mental, crime e justiça. São Paulo, Edusp, pp. 85-104.

Direito Penal. São Paulo, Saraiva, vol. 1.

Inovações do Novo Código Penal.

Rio de Janeiro, Alba.

As prisões em São Paulo (1822 -1940),

São Paulo, Anablume.

O espetáculo das raças: cientistas, instituições e questão racial no Brasil (1970 -1930). São Paulo, Companhia das Letras.

Código Penal da República dos Estados Unidos do Brasil.

Rio de Janeiro, Livraria Garnier.

Recebido para publicação em novembro de 2001.

Aprovado para publicação em março de 2002. 